\title{
O USO DE SISTEMA DE INFORMAÇÕES GEOGRÁFICAS NA PRIORIZAÇÃO DE ÁREAS PARA APROVEITAMENTO MINERAL DE SAIBRO EM ÁREAS DEGRADADAS, UBATUBA, SP
}

\author{
Cláudio José FERREIRA \\ Paulo César FERNANDES DA SILVA
}

\begin{abstract}
RESUMO
No município de Ubatuba existem 116 áreas degradadas pela mineração, que foram avaliadas e classificadas por meio de um Índice de Aproveitamento Mineral desenvolvido no Sistema de Informações Geográficas SPRING. O referido índice leva em consideração variáveis topográficas e variáveis relativas a restrições de uso e ocupação do solo e legais. Os resultados mostram a classificação de seis áreas como sendo de muito alto potencial para aproveitamento e $35 \mathrm{com}$ potenciais de alto a médio. Na primeira etapa de avaliação, o cálculo de volume de material disponível foi efetuado de forma semi-automática por meio de rotina computacional existente no programa SPRING. Em seguida foram aplicados critérios para correção do volume total calculado, que incluíram: a) correção da geometria das curvas de nível desatualizadas; b) índices numéricos atribuídos a restrições sociais e legais e obtidas por meio de operações topológicas. Os resultados foram divididos em cinco intervalos numéricos do Índice de Aproveitamento Mineral que indicam áreas prioritárias para a implantação de lavras de saibro, promovendo de um lado a elaboração e custeio de planos de recuperação de áreas já degradadas, e de outro, $o$ atendimento da demanda local de saibro sem a necessidade de abertura de novas frentes de lavra em áreas melhor preservadas.
\end{abstract}

Palavras-chave: mineração, potencial mineral, degradação ambiental, geoprocessamento, SIG SPRING

\begin{abstract}
The Municipality of Ubatuba (northern coast of São Paulo, SE Brazil) contains 116 sites degraded by mining activities, which were assessed and classified by means of a Mineral Exploitation Index. The Index is based on GIS operations and takes into consideration topographic variables as well as legal variables and land use restrictions. Its application classified six sites as very highly potential for exploitation and 35 as highly to moderately potential. In the first phase of assessment, the volume of bulk material available was calculated semi-automatically using a computer routine present in the SPRING GIS package. This was followed by the application of criteria for the adjustment of bulk volumes, such as a) changes in the topographic geometry and b) numerical scores related to legal and land use restrictions, which were attained through GIS topological operations. The results were sorted into five numerical interval classes that express priorities for the exploitation of residual soil (saibro) based on its mineral potential. The outcomes are thought to be useful in two ways: a) for devising technical and financial schemes for site reclamation; b) for responding to the local demand for construction materials without having to initiate new mining sites in areas that should be preserved instead.
\end{abstract}

Keywords: mining, land degradation, mineral potential, geo-processing, GIS SPRING 


\section{INTRODUÇÃO}

Em Ubatuba, a extração de saibro (material argilo-arenoso proveniente do solo de alteração de rochas granítico-gnáissicas da região), rocha ornamental ("granito verde Ubatuba") e pedra para cantaria (CHIODI et al. 1982, .CHIEREGATI \& MACEDO 1982, BITAR et al. 1985, BITAR 1990, BRAGA et al. 1991, SILVA 1995 e SILVA \& MARTINS 1997) ocasionou grave degradação ambiental no município ao longo das últimas cinco décadas. Ainda que a ação fiscalizadora do poder público, a partir da década de 1990, tenha sido capaz de limitar quase que completamente esse vetor de degradação, por meio do embargo das lavras ilegais, não houve sucesso na promoção da recuperação ambiental das áreas degradadas pela atividade, como apontam os trabalhos de BROLLO et al. (2005) e FERREIRA et al. (2005, 2006, 2007, 2008).

A extração de saibro foi e ainda pode ser considerada estratégica para o desenvolvimento municipal, por seu uso na infra-estrutura civil e na manutenção da rede viária. Ainda que seja um bem mineral abundante e não requeira tecnologias sofisticadas para sua produção, seu aproveitamento desordenado e sem compromisso com a correta finalização da lavra tem significativo potencial de causar problemas ambientais. Tais problemas estão relacionados à dinâmica das águas (alagamento, assoreamento, enchente, turbidez e alteração da acidez de cursos d' água e surgências), estabilidade de encostas (corrida de lama, erosão acelerada, escorregamento), perda da camada de solo superficial, queda e rolamento de blocos, rastejo da encosta e impacto visual. As áreas mineradas degradadas trazem como consequências, a depreciação do patrimônio paisagístico do município, oferecem perigos à população, aos equipamentos do entorno e ao meio ambiente e provocam dificuldade no desenvolvimento legal da atividade econômica de mineração.

De acordo com FERREIRA et al. (2008), o município de Ubatuba apresenta 116 áreas degra-

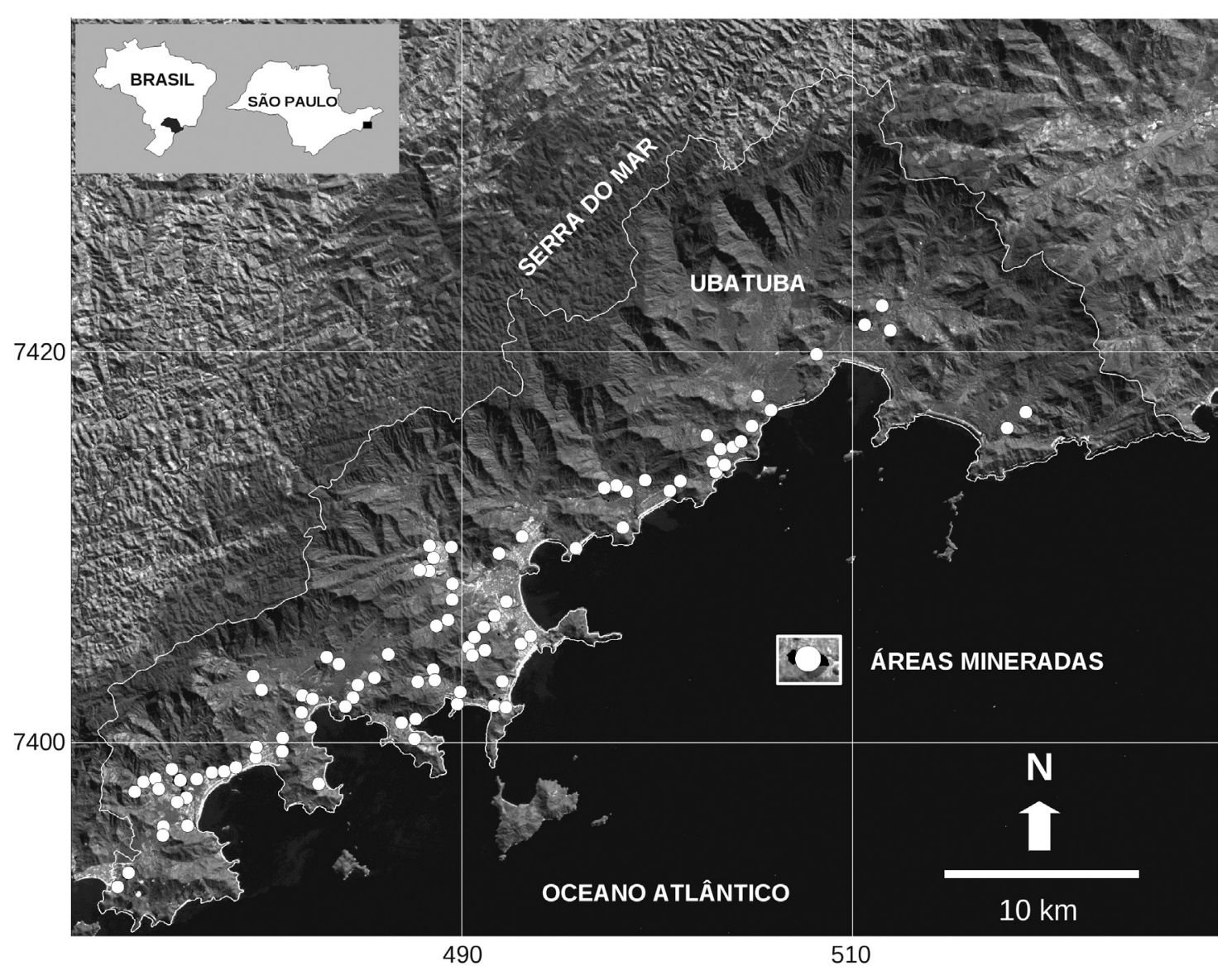

FIGURA 1 - Localização do município de Ubatuba e distribuição das 116 áreas mineradas estudadas. 
dadas pela atividade de mineração de saibro e rocha ornamental (Figura 1). As áreas têm dimensão média em torno de $31.000 \mathrm{~m}^{2}$, com variação entre $800 \mathrm{~m}^{2}$ e $150.000 \mathrm{~m}^{2}$. Apesar das pequenas dimensões, a área total ocupada por essas antigas extrações atinge $3,6 \mathrm{~km}^{2}$, o que representa $0,5 \%$ do território continental de Ubatuba, de $700 \mathrm{~km}^{2}$.

O entendimento das características desses sítios de lavra e a elaboração de uma metodologia de classificação e sistematização do problema constituem o núcleo do estudo intitulado "Diretrizes para a regeneração sócio-ambiental de áreas degradadas por mineração de saibro (caixas de empréstimo), Ubatuba, SP”, conduzido pelo Instituto Geológico em parceria técnica com outras instituições, tendo como beneficiário direto a Prefeitura Municipal. $\mathrm{O}$ referido estudo abordou três aspectos ou demandas principais do poder público municipal e suas interrelações: 1) a necessidade de avaliar a degradação ambiental provocada pela atividade de mineração e recuperar as áreas degradadas; 2) a possibilidade de redução dos riscos impostos a pessoas e bens pelo abandono ou ocupação inadequada desses sítios; e 3) a identificação do potencial de aproveitamento mineral de forma a articular e promover o ordenamento e racionalização da exploração de saibro no município, na medida do possível, compatibilizando-a com outros tipos de uso do solo.

O presente trabalho enfoca o terceiro desses aspectos e tem como objetivo a classificação do aproveitamento mineral das 116 áreas cadastradas com base no cálculo dos volumes disponíveis (potencial mineral strictu sensu) e levando em consideração algumas restrições legais e do uso e ocupação do solo. A principal ferramenta utilizada foi o Sistema de Informação Geográfica SPRING (CÂMARA et al. 1996), por meio do qual foram delimitadas as áreas mineradas com base em ortofotos digitais de 2001, resolução 1m (escala nominal de trabalho em torno de 1:3.000) e realizado o processamento e análise espacial dos dados vetoriais e matriciais.

\section{AS ÁREAS MINERADAS EM UBATUBA}

Ubatuba localiza-se no Litoral Norte do Estado de São Paulo, região de extrema importância para a preservação da biodiversidade. Cerca de $72 \%$ de sua área é ocupada por unidades de conservação de proteção integral que preservam os remanescentes da Mata Atlântica no Estado, bioma que se caracteriza pela alta diversidade de espécies e endemismo (MORELLATO \& HADDAD 2000).
O relevo da região é marcado pelas escarpas da Serra do Mar (ALMEIDA \& CARNEIRO 1998), com amplitudes de mais de 900m (Figura 1). A dissecação desta escarpa originou patamares, condicionados pelas estruturas geológicas, formando maciços e morros alongados (espigões), morros e rampas coluviais, entremeados pelas planícies alúvio-coluviais, passando para planícies litorâneas à medida que se aproxima da costa (PIRES NETO 1998, TOMINAGA et al. 2008).

As litologias presentes na área do município são rochas ígneo-metamórficas dos Complexos Costeiro, Pico do Papagaio, Rio Negro, Charnockito Ubatuba e granitos Caçandoca, Ilha Anchieta, Parati e Parati-Mirim (PERROTA et al. 2005).

A associação entre espessas camadas de solo, que podem atingir dezenas de metros, alta declividade das encostas e elevados índices pluviométricos, com médias dos totais anuais em torno de $2500 \mathrm{~mm}$, favorecem o desenvolvimento de processos de instabilização das vertentes, destacandose os escorregamentos. Além disso, o crescimento urbano desordenado nestes setores naturalmente suscetíveis aos processos de escorregamentos, marcado por ocupações irregulares e pela ausência ou carência de infraestrutura adequada, contribui para o aumento da ocorrência de desastres associados a estes fenômenos (GUIDICINI \& IWASA 1977, LACERDA 2007, TOMINAGA et al. 2008).

Os estudos mais abrangentes sobre os recursos minerais de Ubatuba iniciaram-se na décadas de 70 e 80 . Esses estudos enfocam a atividade de mineração com o viés do aproveitamento econômico (SILVA et al. 1977, CHIEREGATI \& MACEDO 1982, BITAR et al. 1985). Entretanto, já no levantamento executado por CHIODI et al. (1982) denota-se uma incipiente preocupação ambiental, com a inclusão de um item denominado "Lavra e meio ambiente" nas fichas de campo. Todavia, a análise dessas fichas demonstra que tal preocupação frequentemente restringia-se a declarar a não interferência das praças de lavra no meio ambiente.

A visão da atividade de mineração como causadora de impactos ambientais e de perigos geológicos surge a partir do final da década 80 , relacionada à elaboração do relatório sobre a instabilidade da Serra do Mar e situações de risco ("Relatório 60 dias"; SÃO PAULO 1988). Na adoção de suas diretrizes, principalmente na execução de cartas geotécnicas municipais e na implantação do Plano Preventivo de Defesa Civil específico para Escorregamentos nas Encostas da Serra do Mar-PPDC, 
as áreas de lavras são descritas detalhadamente quanto aos seus impactos ambientais e perigos associados com vistas à avaliação dos riscos (BRAGA et al. 1991, BITAR 1990, SILVA 1995 e SILVA \& MARTINS 1997).

FERREIRA (2006), com base nos levantamentos anteriores e em dados inéditos uniformizou os dados disponíveis, adequando-os à visão de que o aproveitamento dos bens minerais no Litoral Norte deve, prioritariamente, submeter-se à recuperação ambiental das áreas paralisadas. A abordagem aliou ainda uma avaliação dos perigos geológicos, da vulnerabilidade e do valor dos elementos do entorno (pessoas e bens) das praças de lavra, informação necessária para a análise de risco. Enquanto BROLLO et al. (2005) e FERREIRA et al. (2006, 2007, 2008) analisaram as áreas mineradas em termos de caracterização e quantificação da degradação ambiental, SANTORO et al. (2007) apresentaram uma análise de risco a escorregamentos associado aos sítios minerados. A figura 2 mostra alguns exemplos de áreas mineradas na escala de afloramento.
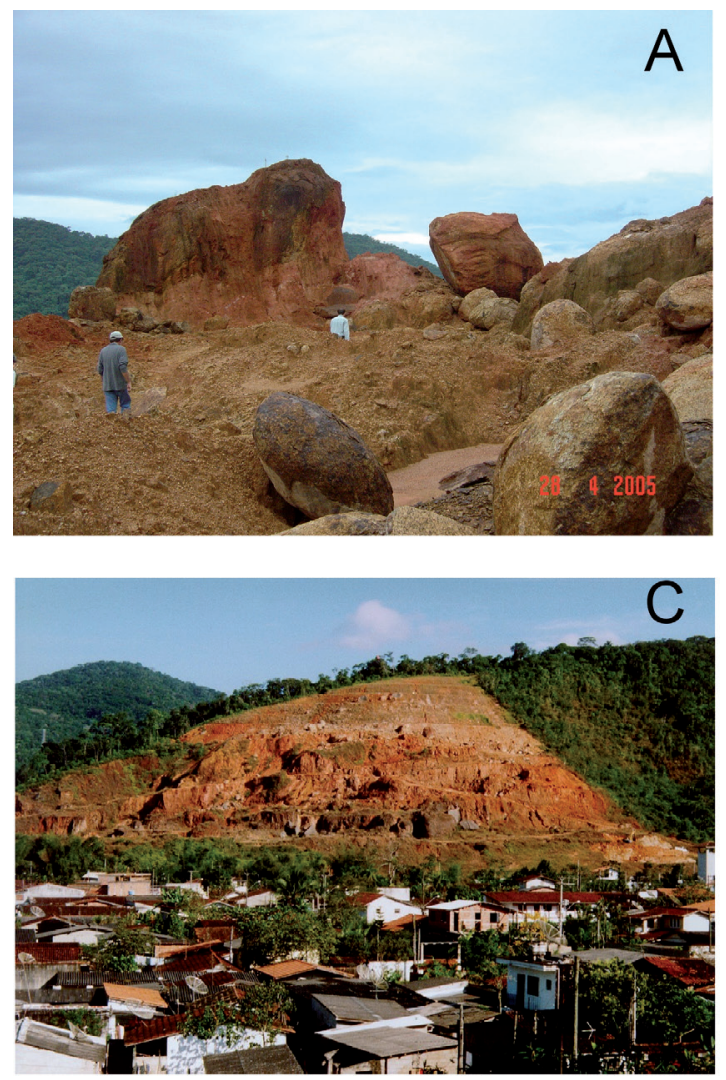

\section{MÉTODOS}

O principal instrumento de organização, processamento e análise dos dados foi o pacote SIG SPRING versão 4.3.3 (CÂMARA et al. 1996). Para tal, criou-se um banco de dados e um projeto onde foram incluídos planos de informação tais como, limites do município, parque estadual e zona de tombamento do CONDEPHAAT, curvas de nível nas escalas 1:10.000 e 1:50.000 e imagens digitais ortorretificadas, originadas de levantamento aerofotogramétrico de 2001 com resolução de $1 \mathrm{~m}$. Inseriu-se ainda um plano de informação cadastral com os pontos das áreas mineradas resultante do geo-referenciamento feito por FERREIRA (2006) a partir de levantamentos anteriores executados por CHIODI et al. (1982), SÃO PAULO (1990), SILVA (1995) e SILVA \& MARTINS (1997) e trabalhos de campo específicos para o presente estudo.

A classificação do aproveitamento mineral de saibro das 116 áreas mineradas foi efetuada na escala 1:3.000, de forma a considerar tanto
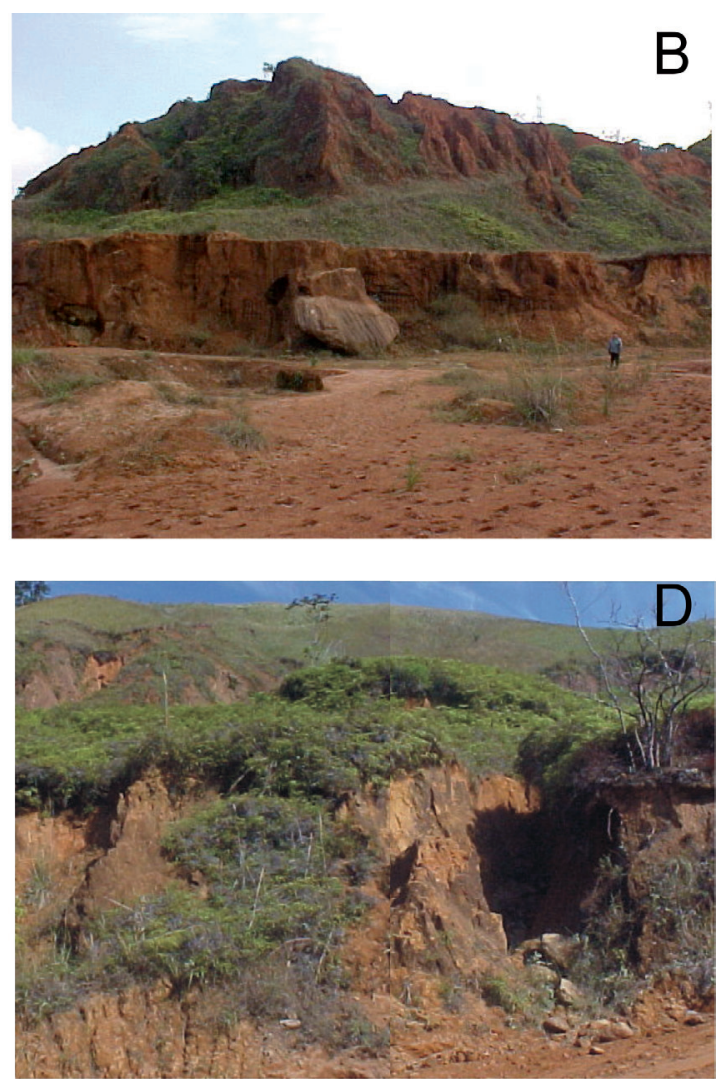

FIGURA 2 - Exemplos de áreas mineradas. A) RM-290, Perequê-Mirim, B) UBA-04, Maranduba, C) RM-332, Ipiranguinha, D) RM-336, Maranduba. 
os atributos relacionados às reservas minerais como uma análise topológica dos atributos relacionados às duas principais restrições legais: os limites do Parque Estadual da Serra do Mar (PESM) e a zona de tombamento da Serra do Mar do CONDEPHAAT.

Por ser o saibro um bem mineral resultante de processos de alteração das rochas e da pedogênese, não existem controles geológicos que diferenciem o material explotável quanto à distribuição de teores e concentrações, como normalmente ocorre com outros tipos de minério. Basicamente, os condicionantes geológicos observados são o grau de alterabilidade das rochas (quanto maior a alterabilidade maior a espessura de solo e maior a quantidade de saibro) e a ocorrência maior ou menor de matacões imersos no solo (o que diminui a quantidade de solo disponível). No entanto, como a variação desses fatores pode ser considerada muito pequena entre as unidades geológicas da região, eles foram considerados constantes no método de cálculo efetuado. Os principais fatores limitantes são as dimensões horizontal e vertical dos polígonos definidos como áreas mineradas, as quais compõem o volume total de material. O modelo geral para determinação do aproveitamento mineral adotado segue cinco etapas, discriminadas a seguir e descritas com maiores detalhes nos itens seguintes.

- Definição dos polígonos representativos das áreas mineradas;

- Cálculo do volume (V1) com base na geometria das áreas mineradas;

- Correção do volume obtido considerando o quanto de material já foi retirado (V2) e cálculo do volume explotável (V3);

- Classificação e re-enquadramento dos volumes em função de restrições legais e de uso e ocupação e cálculo do Índice de Aproveitamento Mineral (IAM);

- Re-enquadramento do índice (IAM) em cinco classes de aproveitamento mineral.

\subsection{Definição dos polígonos das áreas mineradas}

Os polígonos das áreas mineradas foram definidos numa escala nominal em torno de 1:3.000. Os critérios utilizados foram: a) pertencer a um cadastro anterior; b) apresentar solo exposto em área de encosta; c) apresentar encosta com geometria irregular identificada por quebras de relevo lineares, bem como cavidades e ondulações do terreno; d) apresentar feições lineares indicativas de processos erosivos; e) apresentar cobertura vegetal her- bácea-arbustiva; f) mostrar continuidade espacial. Usualmente mais de um critério foi necessário na definição de um sítio como área minerada. Os polígonos assim delimitados (Figura 6) constituíram os objetos de análise no ambiente SIG e tiveram importante função no manejo do banco de dados, pois todos os atributos foram associados a cada polígono (VEDOVELLO et al. 2005).

\subsection{Cálculo do volume total (V1)}

O volume total do bem mineral saibro está condicionado fundamentalmente pela geometria tridimensional da área minerada. O cálculo do volume no SPRING é elaborado a partir de dois planos de informação: um do modelo cadastral, contendo polígonos fechados representativos das áreas mineradas, e outro do modelo numérico, dado por uma grade retangular representativa das cotas altimétricas (Figura 3). A grade numérica retangular foi gerada no SIG SPRING por meio do interpolador vizinho mais próximo (modelagem determinística local), com base nos mapas altimétricos digitais do IGC (escala 1:10.000, disponíveis para a região entre Maranduba e Itamambuca) e do IBGE (escala 1:50.000, disponíveis para as demais regiões). A interpolação por vizinho mais próximo é definida pela escolha de apenas uma amostra para cada ponto da grade. Este tipo de interpolador mantém os valores das amostras na grade, sem gerar valores intermediários. O programa calcula o volume de cada célula a partir do valor central da grade numérica retangular, correspondente a altura (eixo z, cota altimétrica interpolada), multiplicada pela área da célula. Dessa forma, o volume é calculado através das equações abaixo (INPE 2008):

$$
\begin{aligned}
& \mathrm{Vt}=\mathrm{Ac} * \mathrm{Z} 1+\mathrm{Ac} * \mathrm{Z} 2+\mathrm{Ac}^{*} \mathrm{Z} 3+\ldots \mathrm{Ac} * \mathrm{Zn} \\
& (\text { equação 1) }
\end{aligned}
$$

Sendo: $\mathrm{Vt}=$ volume total da área;

$\mathrm{Ac}=$ constante, é o valor da área correspondente à cada célula;

$\mathrm{Zi}=$ valor da altura [cota altimétrica] de cada célula, calculado de acordo com o interpolador utilizado.

$\mathrm{n}=$ número de célula

Logo tem-se que,

$$
\mathrm{Vt}=\mathrm{Ac} \sum_{\mathrm{i}=}^{\mathrm{n}} \mathrm{Zi} \quad \text { (equação 2) }
$$



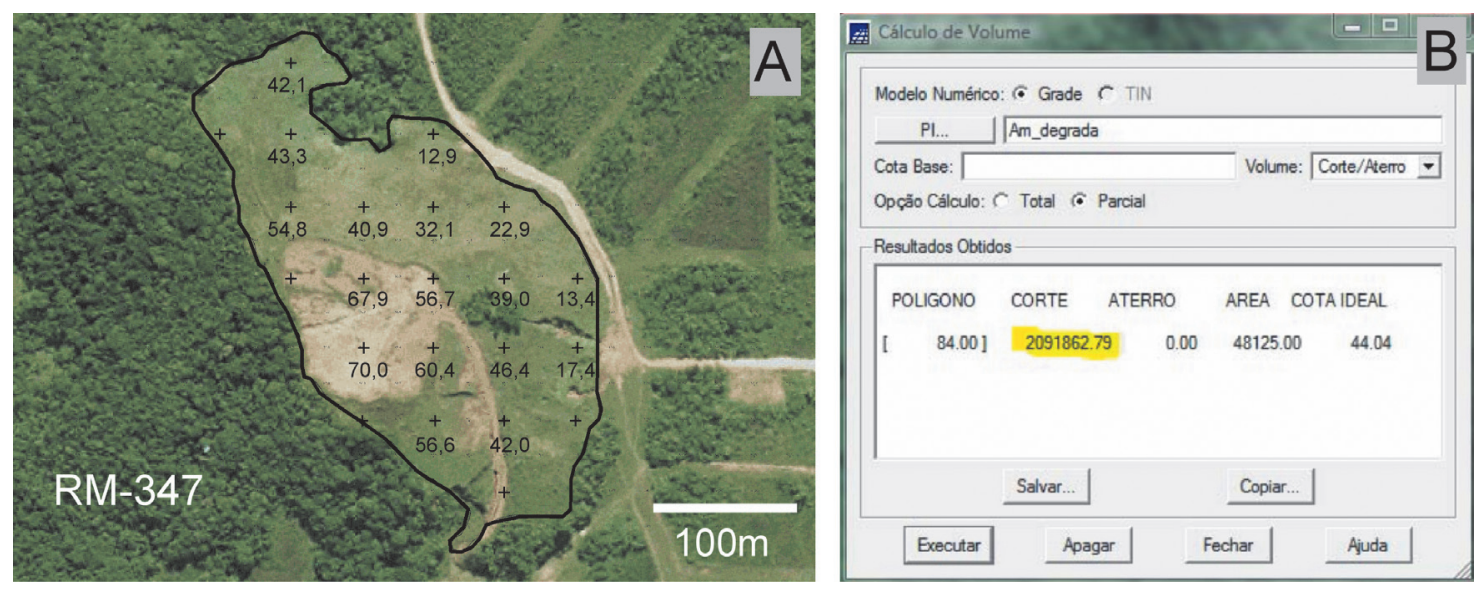

FIGURA 3 - Telas do programa SPRING versão 4.3.3. A) Exemplo de área minerada e grade numérica de cotas altimétricas; B) Tela de cálculo do volume.

Note-se que, de acordo com as equações acima, o volume total para uma determinada área minerada é dado pelo somatório dos volumes de cada célula, situadas a partir de um valor mínimo de cota altimétrica (cota base) até o valor máximo ocorrente dentro do polígono (representativo da área minerada). A área de cada célula é constante, definida de acordo com a resolução estabelecida para a geração da grade numérica.

3.3 Correção em função do material já extraído (V2) e cálculo do volume explotável (V3)

Como descrito acima, o volume total (V1) foi calculado pelo SIG a partir de uma grade numérica originada de curvas de nível cartografadas em 1977 para a região entre Maranduba e Itamambuca (base planialtimétrica do IGC na escala 1:10.000) e em 1972 para as demais áreas (base planialtimétrica do

TABELA 1 - Critérios para correção do volume total (V1) devido mudança da geometria das curvas de nível.

\begin{tabular}{cl}
\hline $\begin{array}{c}\text { Fator de } \\
\text { redução }\end{array}$ & \multicolumn{1}{c}{ Critérios } \\
\hline 1.00 & $\begin{array}{l}\text { sem redução, praticamente não } \\
\text { houve retirada de material } \\
\text { redução de 25\%, para áreas com } \\
\text { pequena retirada de material } \\
\text { redução de 50\%, para áreas com } \\
\text { retirada de material em torno da } \\
\text { metade } \\
\text { redução de } 75 \% \text {, para áreas com } \\
\text { grande retirada de material }\end{array}$ \\
\hline
\end{tabular}

IBGE na escala 1:50.000). Entretanto, essas curvas não refletem as modificações do terreno causadas por extrações de saibro posteriores a essas datas. Com base em critérios empíricos, derivados da análise das ortofotos e da geometria observada na escala de afloramento em campo, definiu-se uma tabela de redutores do volume total (V1), procurando levar em consideração a quantidade de material já retirado (não computado pelo cálculo anterior - Tabela 1).

$\mathrm{O}$ volume obtido (V2) representa uma reserva total que não pode ser aproveitada inteiramente, pois para isso a geometria final da lavra teria que apresentar taludes verticais. Considerou-se a necessidade de se manter uma inclinação final da lavra em torno de $45^{\circ}$, aplicando-se assim um redutor de $50 \%$ do volume, obtendo-se então o volume explotável (V3).

\subsection{Restrições legais e de uso e ocupação do solo}

As etapas anteriores permitiram classificar as áreas mineradas quanto ao seu potencial mineral. Essa classificação, no entanto, não levou em conta fatores sociais e legais vigentes que por vezes tornam inviável o empreendimento ou impõem grandes restrições ao aproveitamento de saibro, ainda que existam reservas em quantidade significativa. Para incorporar essa visão ao modelo de definição do potencial mineral, as 116 áreas em estudo foram agrupadas em três classes, estabelecendo uma gradação de acordo com as restrições legais de uso e ocupação do solo:

- restrições impeditivas: áreas completamente inseridas nos limites do Parque Estadual da Serra do Mar (PESM); 
TABELA 2 - Classes de restrições sociais e legais e intervalos numéricos de reclassificação do potencial mineral.

\begin{tabular}{lcl}
\hline Classe & Intervalo & Critérios \\
\hline $\begin{array}{l}\text { 1-Restrições } \\
\text { impeditivas }\end{array}$ & $0,00-0,33$ & $\begin{array}{l}\text { Áreas com volumes inviáveis de exploração (volumes explotáveis } \\
\text { menores que 120.000 } \mathrm{m}^{3} \text { ) ou situadas completamente no interior do } \\
\text { Parque Estadual da Serra do Mar }\end{array}$ \\
$\begin{array}{l}\text { 2-Restrições } \\
\text { severas }\end{array}$ & $0,33-0,66$ & $\begin{array}{l}\text { Áreas situadas parcialmente no interior do Parque Estadual da } \\
\text { Serra do Mar ou totalmente no interior de área tombada pelo } \\
\text { CONDEPHAAT }\end{array}$ \\
$\begin{array}{l}\text { 3-Restrições } \\
\text { moderadas }\end{array}$ & $0,66-1,00$ & $\begin{array}{l}\text { Áreas contidas parcialmente no interior de área tombada pelo } \\
\text { CONDEPHAAT ou situadas completamente fora da área tombada }\end{array}$ \\
\hline
\end{tabular}

- restrições severas: áreas que interceptam o limite do PESM ou situam-se completamente dentro dos limites da área tombada da Serra do Mar;

- restrições moderadas: áreas contidas parcialmente no interior de área tombada pelo CONDEPHAAT ou situadas completamente fora da área tombada e do PESM.

Nesse sentido, a partir de consultas topológicas realizadas no SIG e enquadramento das áreas mineradas nas três classes mencionadas, os volumes explotáveis calculados (V3) foram reajustados conforme os intervalos numéricos das classes apresentadas na tabela 2 .

Em relação à quantidade de material, adotouse um limite mínimo de $120.000 \mathrm{~m}^{3}$, para enquadramento na classe de restrição impeditiva. Ou seja, as áreas cujo volume explotável situa-se abaixo deste valor, foram consideradas como inviáveis sob o ponto de vista econômico, o que representa, na prática, uma restrição impeditiva ao empreendimento. Esse limite mínimo foi estimado considerando-se uma produção média anual de $48.000 \mathrm{~m}^{3}$ e uma vida útil média de cinco anos para o empreendimento, conforme dados obtidos da análise dos processos de licenciamento ambiental (FERREIRA 2004). A avaliação desses dados indicou uma reserva explotável média de $240.000 \mathrm{~m}^{3}$. Desse modo, o limite mínimo adotado no presente trabalho representa a metade do valor médio, ou seja, um patamar mínimo de reserva, do ponto de vista econômico e de operacionalidade da lavra, para que o empreendimento possa ser iniciado.

$\mathrm{O}$ enquadramento das áreas nas três classes de restrições e cálculo do Índice de Aproveitamento Mineral (IAM) foi efetuado através das equações:
A- Restrições impeditivas $(0,00-0,33)$

$\underset{\text { área } \mathrm{An}}{\mathrm{IAM}}=\frac{\mathrm{V} 3_{\mathrm{An}}-\mathrm{V} 3_{\min }}{\mathrm{V} 3_{\max }-\mathrm{V} 3_{\min }} \times 0,33$

(equação 3)

B- Restrições severas $(0,33-0,66)$

$\underset{\text { área An }}{\mathrm{IAM}}=\left\{\frac{\mathrm{V} 3_{\mathrm{An}}-\mathrm{V} 3_{\min }}{\mathrm{V} 3_{\text {max }}-\mathrm{V} 3_{\text {min }}} \times 0,33\right\}+0,33$

(equação 4)

C- Restrições moderadas $(0,66-1,00)$

$\underset{\text { área } A n}{\mathrm{IAM}}=\left\{\frac{\mathrm{V} 3_{\mathrm{An}}-\mathrm{V} 3_{\min }}{\mathrm{V} 3_{\max }-\mathrm{V} 3_{\text {min }}} \times 0,33\right\}+0,66$

(equação 5)

Onde: IAM = Índice de Aproveitamento Mineral para uma determinada área (An);

V3 = valor V3 para uma determinada área (An);

$\mathrm{V} 3_{\text {min }}=$ valor mínimo do grupo de amostras;

$\mathrm{V} 3_{\text {max }}=$ valor máximo do grupo de amostras.

0,33 e $0,66=$ índices aplicado para enquadrar o valor obtido para o intervalo entre $0,00-0,33$, 0,33-0,66 e 0,66-1,00.

3.5 Reclassificação dos Índices de Aproveitamento Mineral

Para fins de síntese e discussão, os valores dos índices (IAM) obtidos para as 116 áreas mineradas no município de Ubatuba, estabelecidos den- 
tro do intervalo de 0 a 1 , foram enquadrados em cinco classes de aproveitamento mineral conforme mostra a tabela 3 .

TABELA 3 - Classes de aproveitamento de saibro das áreas mineradas.

\begin{tabular}{lcc}
\hline $\begin{array}{c}\text { Classe de } \\
\text { Aproveitamento }\end{array}$ & Intervalo & $\begin{array}{c}N^{o} \text { de pontos } \\
\text { na classe }\end{array}$ \\
\hline AM1 - Muito baixa & $0,00<\mathrm{IAM} 1 \leq 0,20$ & 55 \\
AM2 - Baixa & $0,20<\mathrm{IAM} 2 \leq 0,40$ & 20 \\
AM3 - Média & $0,40<\mathrm{IAM} 3 \leq 0,60$ & 05 \\
AM4 - Alta & $0,60<\mathrm{IAM} 4 \leq 0,80$ & 30 \\
AM5 - Muito Alta & $0.80<\mathrm{IAM} 5 \leq 1,00$ & 06 \\
\hline
\end{tabular}

\section{RESULTADOS}

Os volumes explotáveis de saibro (V3) variam de zero a 6 milhões de metros cúbicos. $\mathrm{O}$ valor médio obtido foi de 509.954,96 $\mathrm{m}^{3}$ e a mediana, de $164.161,07 \mathrm{~m}^{3}$. O total calculado chega a cerca de 59 milhões de metros cúbicos de saibro. A figura 4 mostra os limites das classes e o número de áreas em relação ao Índice de Aproveitamento Mineral, a figura 5, a distribuição espacial dos pontos nas cinco classes definidas e a figura 6 apresenta as seis áreas com maior Índice de Aproveitamento Mineral (classe Muito Alta de potencial mineral) em imagem ortorretificada.

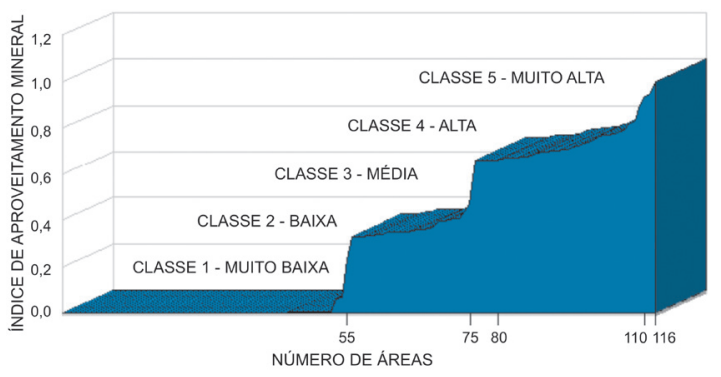

FIGURA 4 - Distribuição do Índice de Potencial Mineral em ordem crescente de valor e limites das cinco classes de aproveitamento mineral definidas.

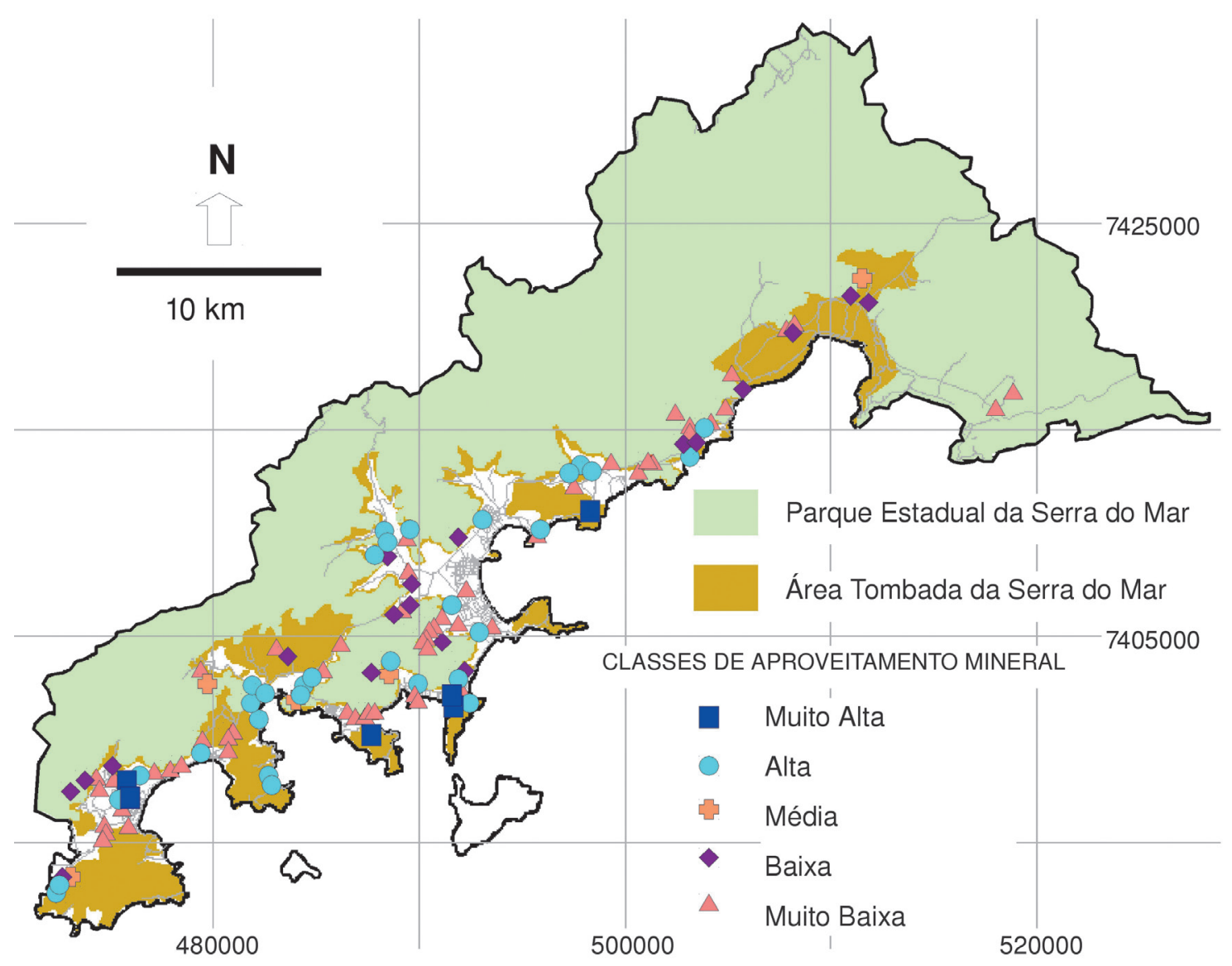

FIGURA 5 - Distribuição e classificação das áreas mineradas quanto ao Índice de Aproveitamento Mineral (IAM). 



FIGURA 6 - Exemplos de áreas mineradas e dos IAM calculados para a classe Muito Alta. Barra $=100 \mathrm{~m}$. 
Na classe 1 (índice muito baixo de aproveitamento mineral) foram definidas 55 áreas, das quais 53 apresentam volumes menores que $120.000 \mathrm{~m}^{3}$ e não possuem reservas que possam ser consideradas viáveis para empreendimentos minerários, ainda que eventualmente possa ser extraído algum saibro, em conjunto com algum outro uso. Duas áreas apresentam reservas explotáveis (RM311 e RM313, Figura 5) que, no entanto, foram incluídas na classe de restrições impeditivas (completamente inseridas nos limites do Parque Estadual da Serra do Mar).

Na classe 2 (índice baixo de aproveitamento mineral) foram incluídas 20 áreas, das quais duas situam-se no interior do Parque Estadual da Serra do Mar (PESM) (UBA09 e UBA10), e as demais, ou interceptam o limite do PESM ou situam-se completamente dentro dos limites da área tombada da Serra do Mar (Figura 5). Os volumes explotáveis para essa classe variam de $240.000 \mathrm{~m}^{3}$ até 5 milhões de $\mathrm{m}^{3}$.

Na classe 3 (índice médio de aproveitamento mineral) foram incluídas apenas cinco áreas, todas interceptando o limite do PESM ou situadas completamente dentro dos limites da área tombada da Serra do Mar (Figura 5). Os volumes explotáveis variam de 1,5 a 2,7 milhões de $\mathrm{m}^{3}$ de saibro.

$\mathrm{Na}$ classe 4 (índice alto de aproveitamento mineral) foram incluídas 30 áreas, das quais, apenas uma (RM389) intercepta o limite do PESM (Figura 5). As demais áreas estão enquadradas na classe de restrições moderadas quanto aos aspectos legais. Os volumes explotáveis variam de 130 a $825 \mathrm{mil} \mathrm{m}^{3}$ de saibro, exceto para o ponto RM389 que apresenta volume explotável de 6,0 milhões de $\mathrm{m}^{3}$.

$\mathrm{Na}$ classe 5 (índice muito alto de aproveitamento mineral) foram incluídas apenas seis áreas (Figuras 5 e 6), todas situadas fora do limite do PESM e inseridas na classe moderada quanto aos aspectos legais. Os volumes explotáveis variam de 950 mil a 1,9 milhões de $\mathrm{m}^{3}$ de saibro.

\section{DISCUSSÃO}

O método semi-automático apresentado anteriormente não substitui estudos detalhados para cubagem e cálculo de reserva mineral, e não deve ser utilizado com esse propósito. Trata-se de um método expedito desenvolvido experimentalmente, com o intuito de responder às necessidades do poder público municipal na gestão da atividade de mineração e dos impactos decorrentes. Nesse sentido, assinala-se a opção por recursos tecnológicos, tais como o uso de imagens aéreas e do software gratuito SPRING para análise espacial de dados, que constituem o cer- ne do método e permitem a implementação de uma técnica prática e efetiva para comparação da reserva mineral potencial entre diferentes áreas impactadas e/ou degradadas pela mineração.

As áreas denominadas RM390 e RM371 podem ser utilizadas para fins de comparação dos resultados ora obtidos e de estudos anteriores. Cálculos de reserva encontrados em estudos detalhados apresentados no Plano de Controle Ambiental (PCA) submetido à CETESB (ver FERREIRA 2004) mostram reservas de $1.277 .750 \mathrm{~m}^{3}$ e de $200.000 \mathrm{~m}^{3}$, respectivamente, enquanto os valores calculados no presente estudo são de $1.529 .726 \mathrm{~m}^{3}$ e 213.644 .41 $\mathrm{m}^{3}$, respectivamente, para as mesmas áreas, o que mostra a boa aproximação do método desenvolvido.

Em relação ao trabalho desenvolvido por SARAIVA (2001) no Município de Caraguatatuba, nota-se que, para a estimativa de potencial mineral, aquele autor considerou uma espessura média constante de 20 metros, valor este aplicado de forma generalizada às 42 áreas com potencial mineral para saibro, que totalizaram $8.857 .473 \mathrm{~m}^{2}$ e volumes estimados da ordem de 177 milhões de metros cúbicos, denotando um volume médio de $19,98 \mathrm{~m}^{3} / \mathrm{m}^{2}$.

No presente estudo, os valores de espessura utilizados para o cálculo de volume foram determinados individualmente, por meio da interpolação previamente descrita, respectiva a cada célula utilizada para o cálculo do volume em cada área. Em outras palavras, os valores de espessura têm uma natureza iterativa, em função do condicionante topográfico em que a variabilidade espacial dos valores de cota altimétrica é definida no momento da geração da grade numérica. Adotou-se como premissa que o topo rochoso situava-se abaixo da cota altimétrica mínima (linha de base), assim como não se considerou no cálculo do volume de saibro a influência da possível existência de matacões imersos no solo. O método aqui apresentado indica que as 116 áreas mineradas para saibro no município de Ubatuba ocupam cerca de 3.600.000 $\mathrm{m}^{2}$, com um volume total estimado de cerca de 59 milhões de metros cúbicos de saibro, o que denota um volume médio de $16,39 \mathrm{~m}^{3} / \mathrm{m}^{2}$. Aparentemente, os menores volumes global e médio estimados para o município de Ubatuba não expressam, em relação ao trabalho de SARAIVA (2001), reservas minerais mais pobres ou escassas, mas sim uma maior precisão do método aqui apresentado.

SARAIVA (2001) caracteriza o potencial mineral para saibro no município de Caraguatatuba de acordo com aspectos geológicos, geomorfológicos, e de uso e ocupação do solo, enfocando as restrições de 
ordem legal e ambiental. Nesse sentido, como no presente estudo, o autor adotou os limites do PESM e da zona de tombamento do CONDEPHAAT como critérios de restrição. Ademais, SARAIVA (2001) adota ainda as Áreas de Preservação Permanente (APP) definidas pelo Código Florestal, tais como topo de morros e corredores de 30 metros em torno de drenagens, como critério de restrição e reclassificação das áreas quanto ao potencial, critérios não utilizados no presente estudo.

Ressalta-se que mesmo as áreas identificadas no presente trabalho como de potencial mineral alto a muito alto, enquadradas na classe menos restritiva (moderada), podem apresentar outros limitantes à exploração do saibro na região. Tais limitantes envolvem aspectos diversos como a situação fundiária indefinida, dificuldades no atendimento das exigências de licenciamento minerário e ambiental, que incluem a proximidade de área urbana consolidada ou em consolidação, de rodovias estaduais e de mata preservada, além da possível interferência em áreas de proteção permanente (APPs), como apontado acima. Tais fatores limitantes não foram incluídos na presente análise, mas constituem restrições adicionais que devem ser levadas em conta nos estudos de detalhe voltados à implementação de empreendimentos minerários.

A abordagem semi-automática explorou o interpolador vizinho mais próximo, para gerar a grade retangular de cotas altimétricas, o que segundo alguns autores (ex. CAMARGO \& FUCKS 2001, DRUCK et al. 2004) apresenta características que limitam o seu uso em determinadas aplicações. O referido interpolador utiliza apenas valores reais absolutos das amostras, sem gerar valores intermediários, o que define limites de grande contraste. Outra característica deste interpolador é a distribuição espacial apenas em escalas (distâncias) pequenas. No entanto, considerando-se que no presente estudo a quase totalidade dos polígonos representativos das áreas mineradas possui dimensões relativamente reduzidas (escala gráfica 1:3.000), os efeitos locais da distribuição e variabilidade espacial do parâmetro estudado (no caso, as cotas altimétricas) são detectados a contento. Ao que tudo indica, a utilização do interpolador vizinho mais próximo no tratamento de cotas altiméticas é adequada para o cálculo dos volumes.

\section{CONCLUSÕES}

No presente estudo definiu-se um Índice de Aproveitamento Mineral (IAM) do saibro para as 116 áreas previamente mineradas e degradadas em Uba- tuba. Esse índice considera além das reservas do bem mineral existentes, restrições de ordem legal quanto à localização da área em relação aos limites do Parque Estadual e da área tombada da Serra do Mar.

Cerca de $65 \%$ das áreas estudadas foram enquadradas nas classes Muito Baixa e Baixa do IAM, tanto por não apresentarem reservas economicamente viáveis $\left(<120.000 \mathrm{~m}^{3}\right)$, quanto por se enquadrarem em classes de restrições impeditivas; enquanto cerca de $31 \%$ das áreas enquadram-se nas classes Alta e Muito Alta. Deve-se ressaltar que não obstante a potencialidade mineral ser alta, tais áreas ainda apresentam restrições de uso e ocupação, como proximidade de área urbana consolidada ou em consolidação, rodovias estaduais e mata preservada, que devem ser levadas em conta para a implementação de empreendimentos minerários.

Os resultados mostram que o aproveitamento mineral pode ser uma alternativa de geração de recursos e de implementação de um plano de recuperação ambiental para cerca de 40 áreas degradadas pela mineração em Ubatuba. O aproveitamento mineral em algumas dessas áreas já degradadas teria a vantagem adicional de evitar a abertura de novas frentes de lavras em áreas ainda não impactadas pela atividade de mineração.

\section{AGRADECIMENTOS}

Os autores agradecem à FAPESP pelo suporte financeiro (processo 03/07182-5) e aos revisores anônimos da Revista do Instituto Geológico.

\section{REFERÊNCIAS BIBLIOGRÁFICAS}

ALMEIDA, F.F.M. \& CARNEIRO, C.D.R.1998. Origem e evolução da Serra do Mar. Revista Brasileira de Geociencias, 28:137-150.

BITAR, O.Y. 1990. Mineração e usos do solo no litoral paulista: estudo sobre conflitos, alterações ambientais e riscos. Instituto de Geociências, Universidade Estadual de Campinas, Campinas, Dissertação de Mestrado, 162p.

BITAR, O.Y.; CAMPOS, H.C.N.S.; LEMOS, A.C.P.N. 1985. Planejamento e manejo minerário municipal - a experiência no município de Ubatuba. In: SBG-SP, SIMPÓSIO REGIONAL DE GEOLOGIA, 5, São Paulo, Atas, 1: 99-114.

BRAGA, T.O.; FORNASARI FILHO, N.; SOARES, P.V. 1991. Abordagem ambiental sobre 
a atividade de mineração na Carta Geotécnica do município de Ubatuba-SP. In: SBG-SP, SIMPÓSIO REGIONAL DE GEOLOGIA, 6, São Paulo, Atas, 353-359.

BROLLO, M.J.; FERREIRA, C.J.; FERNANDESDA-SILVA, P.C.; TOMINAGA, L.K.; VEDOVELLO, R.; GUEDES, A.C.M.; LOPES, E.A.; OLIVEIRA, A.R.; UMMUS, M.E.; CRIPPS, J.C. 2005. Caracterização das áreas degradadas por mineração de saibro em Ubatuba: condicionantes para a sua recuperação ambiental. In: ABGE, CONGRESSO BRASILEIRO DE GEOLOGIA DE ENGENHARIA E AMBIENTAL, 11, Florianópolis, Anais, CD-ROM.

CAMARGO, E.C.G. \& FUCKS, S.D. 2001. Geoestatística: Fundamentos e Aplicações. In: G. Câmara (coord.) Geoprocessamento: Teoria e Aplicações. São José dos Campos, Instituto Nacional de Pesquisas Espaciais INPE, disponível on-line http://www.dpi.inpe.br/gilberto/ livro. Consultado em 02 de janeiro de 2007.

CÂMARA, G.; SOUZA, R.C.M.; GARRIDO, J. 1996. SPRING: Integrating remote sensing and GIS by object-oriented data modelling. Computers \& Graphics, 20:(3) 395-403.

CHIEREGATI, L.A. \& MACEDO, A.B. 1982. Economia mineral das rochas ornamentais. In: SBG, CONGRESSO BRASILEIRO DE GEOLOGIA, 32, Salvador, Anais, 3: 1191-1198.

CHIODI, D.K.; THEODOROVICZ, A.M. de G.; THEODOROVICZ, A.; SILVA, L.M. 1982. Projeto planejamento minerário na ocupação do solo em área de atuação da SUDELPA. São Paulo, Governo do Estado de São Paulo, Secretaria de Economia e Planejamento, Superintendência do Desenvolvimento do Litoral Paulista - SUDELPA, Relatório Técnico, 2 v.

DRUCK, S.; CARVALHO, M.S.; CÂMARA, G.; MONTEIRO, A.V.M. 2004. Análise Espacial de Dados Geográficos. Brasília, EMBRAPA, 210p.

FERREIRA, C.J. 2004. Diretrizes para a regeneração sócio-ambiental de áreas degradadas por mineração de saibro (caixas de empréstimo), Ubatuba, SP. São Paulo, Instituto Geológico, Relatório Técnico FAPESP, 52p., Anexo 3.
FERREIRA, C.J. 2006. Hazards related to small mining of minerals for use in construction (sand, stone and residual soil) in the North Coast of State of Sao Paulo, Brazil. In: INTERNATIONAL DISASTER REDUCTION CONFERENCE, 1, Davos, Proceedings, 1: 250.

FERREIRA, C.J.; FERNANDES-DA-SILVA, P.C.; BROLLO, M.J.; CRIPPS, J.C. 2006. Dereliction problems from exploitation of residual soil and ornamental stone at Ubatuba, São Paulo State, Brazil. In: THE IAEG CONGRESS, 10, Nottingham, Proceedings, CDROM, paper 146, 10p.

FERREIRA, C.J.; BROLLO, M.J.; UMMUS, M.E.; NERY, T.D. 2007. Definição e quantificação de indicadores da degradação ambiental de áreas mineradas em Ubatuba, Estado de São Paulo. In: SIMPÓSIO BRASILEIRO DE CARTOGRAFIA GEOTÉCNICA E GEOAMBIENTAL, 6, Uberlândia, Anais, CD-ROM.

FERREIRA, C.J., BROLLO, M.J., UMMUS, M.E., NERY, T.D. 2008. Indicadores e quantificação da degradação ambiental em áreas mineradas, Ubatuba (SP). Revista Brasileira de Geociências, 38(1): 141-152.

FERREIRA, C.J.; FERNANDES-DA-SILVA, P.C.; FURLAN, S.A.; BROLLO, M.J.; TOMINAGA, L.K.; VEDOVELLO, R.; GUEDES, A.C.M.; FERREIRA, D.F.; EDUARDO, A.S.; AZEVEDO SOBRINHO, J.M.; LOPES, E.; CRIPPS, J.C.; PERES, F.; ROCHA, G. 2005. Devising strategies for reclamation of derelict sites due to mining of residual soil (Saibro) at Ubatuba, North Coast of Sao Paulo State, Brazil: the views and roles of stakeholders. Sociedade \& Natureza, Special Issue: 643-660.

GUIDICINI, G. \& IWASA, O.Y. 1977. Tentative correlation between rainfall and landslides in a humid tropical environment. Bull. Eng. Geol. Env., 16:13-20.

INPE. 2008. SPRING 5.0 - Ajuda do programa. Disponível em http:/www.dpi.inpe.br/ spring/ english/download.php. Consultado em 28 de julho de 2008 .

LACERDA, W.A. 2007 Landslide initiation in saprolite and colluvium in southern Brazil: 
Field and laboratory observations. Geomorphology, 87:104-119.

MORELLATO, L.P.C. \& HADDAD, C.F.B. 2000. Introduction: The Brazilian Atlantic Forest. Biotropica, 32(4b):786-792.

PERROTTA, M. M.; SALVADOR, E. D.; LOPES, R. da C.; D`AGOSTINO, L.Z.; PERUFFO, N.; GOMES, S.D.; LACERDA FILHO, J.V. de. 2005. Mapa Geológico do Estado de São Paulo - Escala 1:750.000. Brasília, CPRM.

PIRES NETO, A. G. 1998. Compartimentação Morfoestrutural e Relevos do Planalto Atlântico e Província Costeira no Leste de São Paulo. Geociências, 2(17): 445-468.

SANTORO, J.; MARCHIORI-FARIA, D.G.; ROSSINI-PENTEADO, D.; FERREIRA, C.J.; ARMANI, G. 2007. Mapeamento de áreas de risco a escorregamentos, escala 1:3.000, em áreas de mineração de saibro, UbatubaSP. Santos, SP. In: SIMPÓSIO BRASILEIRO DE DESASTRES NATURAIS E TECNOLÓGICOS, 2, Santos, Anais, CD-ROM.

SÃO PAULO. 1988. Instabilidade da Serra do Mar no Estado de São Paulo - situações de risco. São Paulo, Secretaria de Estado da Ciência e Tecnologia (SCT): Secretaria de Estado do Meio Ambiente (SMA). Relatório Técnico, $4 \mathrm{v}$.

SÃO PAULO. 1990. Carta geotécnica do município de Ubatuba, SP. Secretaria de Estado do Meio Ambiente (SMA) - Instituto Geológico: Secretaria de Estado da Ciência e Tecnologia (SCT): Instituto de Pesquisas Tecnológicas. Relatório Técnico, $2 \mathrm{v}$.

SARAIVA, F.A. 2001. Áreas de Empréstimo no Município de Caraguatatuba - SP: Avaliação da Situação Atual, Perspectivas e Propostas. Instituto de Geociências, Universidade de São Paulo, São Paulo, Dissertação de Mestrado, 105p.

SILVA, A. T. S. F. da; CHIODI FILHO, C. ; CHIODI, D. K.; PINHO FILHO, W. D. de. 1977. Projeto Santos - Iguape. Brasília, Ministério da Minas e Energia. Convênio DNPMCPRM, Relatório Técnico, $3 \mathrm{v}$.

SILVA, F. L. de M. 1995. O risco geológico associado à ocupação de áreas de mineração no município de Ubatuba (SP). Instituto de Geociências, Universidade Estadual de Campinas, Campinas, Dissertação de Mestrado, 80p.

SILVA, F. L. de M. \& MARTINS, L. A. M. 1997. Risco geológico associado à ocupação de áreas de mineração no município de Ubatuba (SP). In: SIMPÓSIO DE GEOLOGIA DO SUDESTE, 6, Itatiaia, Atas, 309-310.

TOMINAGA, L.K.; ROSSINI-PENTEADO, D.; FERREIRA, C.J.; VEDOVELLO, R.; ARMANI, G. 2008. Avaliação do perigo de escorregamentos por meio da análise de múltiplos fatores geoambientais. In: CONGRESSO BRASILEIRO DE GEOLOGIA DE ENGENHARIA E AMBIENTAL, 12, Porto de Galinhas, Anais, CD-ROM.

VEDOVELLO, R.; SULTANUM, H. J.; FERREIRA, C.J., TORREJON, R. A., TOMINAGA, L. K., TAVARES, R. 2005. Modelo conceitual e de programação para a obtenção e atualização automática de cartas de riscos em Sistemas Gerenciadores de Informações Geoambientais - SGIG. In: CONGRESSO BRASILEIRO DE GEOLOGIA DE ENGENHARIA E AMBIENTAL, 11, Florianópolis, Anais, 2327 - 2339.

\section{Endereço dos autores:}

Cláudio José Ferreira e Paulo César Fernandes da Silva - Seção de Geologia Aplicada e Ambiental, Instituto Geológico, Secretaria do Meio Ambiente do Estado de São Paulo, Avenida Miguel Stéfano, 3900, CEP 04301-903, Água Funda, São Paulo, SP. E-mails: cferreira@igeologico.sp.gov.br, paulo.fernandes@ igeologico.sp.gov.br 